\title{
The Significance of Translating the Puns in Shakespeare’s Sonnets
}

\author{
ZHANG Cheng-zhi \\ Hebei University, Baoding, China; \\ UniversitiSains Malaysia, Penang, Malaysia
}

\author{
Goh Sang Seong \\ UniversitiSains Malaysia, Penang, Malaysia
}

\begin{abstract}
Pun is an important rhetoric device in literature. It is especially popular in the Elizabeth Age. William Shakespeare was a great punster, and he made a lot of puns in his sonnets. The objective of this paper is to call readers' and translators' attention that the puns should be given appropriate attention. This paper finds that puns are significant play a very important role in Shakespeare's Sonnets, and that puns were not given appropriate attention in the Chinese translation. Without understanding the puns, one can never fully understand the sonnets. Poetry is difficult to translate, and puns make it more difficult. However, translating the sonnets without translating the puns is only a half translation.
\end{abstract}

Keywords: pun, William Shakespeare, sonnets, translation

\section{Introduction}

From about 1591 to 1594, William Shakespeare composed 154 sonnets, which was first published in 1609, better known as the 1609 Quarto. Each of Shakespeare's sonnets has 14 lines, except Sonnet 99, which has 15 lines, and Sonnet 126, which has 12 lines. The rhyme pattern is "ababcdcdefefgg", and the rhythmic pattern is the iambic pentameter. "The first 126 sonnets are concerned with the poet's relationship with a young man" (Ridden, 1982, p. 18). From Sonnet 127 to 152, the central character is a Dark Lady, while the rest two sonnets "can be regarded as separate from the rest of the sequence" (Ridden, 1982, p. 18). The objective of this paper is to call readers' and translators' attention that the puns should be given special attention.

\section{Shakespeare Puns in a Great Quantity}

Shakespeare used puns in his works most frequently, because he was "greatly given to punning, both in comic and in serious contexts" (Drabble, 2000, p. 825), and "Wordplay was a game the Elizabethans played seriously" (Mahood, 1968, p. 9). LI Xin-hua (2000) pointed out, "Shakespeare was a great master of creating puns. According to incomplete statistics, Shakespeare had created more than 3,000 puns in his works” (p. 198). According to the most preservative count, Romeo and Juliet (1987) has at least 175 puns. Macbeth (2004) has 114 puns, "Lover's Labour's Lost with over two hundred; the Henry IV plays with a hundred and fifty apiece; Much Ado and All's Well with more than a hundred each. The average number of puns in a play by Shakespeare is seventy-eight” (Mahood, 1968, p. 164).

ZHANG Cheng-zhi, associate professor, Foreign Lanuages College, Hebei University; Ph.D. candidate, School of Humanities, UniversitiSains Malaysia.

Goh Sang Seong, Ph.D., School of Humanities, UniversitiSains Malaysia. 
Ingram and Redpath (1978, p. 362) made A Key to Word-Play in the Sonnets, in which they listed 35 pun words. Most of these pun words appeared at least twice in Shakespeare's Sonnets (1978). However, these are not all the pun words that Shakespeare used in the sonnets. Since the editors added, "There are in addition frequent plays on other words which, being so utilized only once, are not listed here but discussed in the relevant notes". For example, "lie” in Sonnet 138:

Therefore I lie with her, and she with me,

And in our faults by lies we flatter’d be. (Ingram \& Redpath, 1978, p. 319)

Based on the list and some other resources, the authors made a table of pun words that Shakespeare used in the sonnets (see Table 1).

Table 1

List of Pun Words in Shakespeare's Sonnets

\begin{tabular}{|c|c|c|c|}
\hline Pun word & Sonnet/line & Pun word & Sonnet/line \\
\hline Antique & $17 / 12 ; 19 / 10$ & Rite & $23 / 6$ \\
\hline Arrest & $74 / 1$ & Sad & Frequent \\
\hline Art & Frequent * & Sadly & $8 / 1$ \\
\hline Assail & $41 / 6 ; 70 / 10$ & Servant & $57 / 8 ; 146 / 9$ \\
\hline Base & $33 / 5 ; 34 / 3 ; 100 / 4$ & Shadow & $43 / 5 / 5 / 6$ \\
\hline Chest & $48 / 9$ & Son/sun & $33 / 14$ \\
\hline Conscience & $151 / 1 / 2 / 13$ & State & $29 / 2 / 10 / 14$ \\
\hline Dear & $30 / 4 ; 48 / 14 ; 87 / 1 ; 110 / 3$ & Steal & $33 / 8 ; 63 / 8 ; 92 / 1 ; 104 / 10$ \\
\hline Engraft & $15 / 14$ & Suit & $127 / 10 ; 132 / 12$ \\
\hline Eye & $148 / 8$ & Tomb & $83 / 12$ \\
\hline Fair & Frequent & Travel & $27 / 2$ \\
\hline Figure & $104 / 9 / 10$ & True & Frequent \\
\hline Field & $2 / 2$ & Truly & 21/9; 77/5; 82/11/11; 132/5 \\
\hline Fool & 57/13/14; 124/13/14 & Truth & Frequent \\
\hline Husbandry & $3 / 6 ; 13 / 10$ & Use & $4 / 7 / 14 ; 6 / 5 ; 48 / 3 ; 134 / 10$ \\
\hline Lovely & Frequent & User & 9/12; \\
\hline Loveliness & $4 / 1$ & Virtuous & $16 / 7 ; 72 / 5$ \\
\hline Made & $138 / 1$ & Wake & $61 / 13$ \\
\hline Morn/mourn(ing) & $132 / 5 / 9 / 11$ & Watch & $61 / 13$ \\
\hline Pretty & $41 / 1 ; 132 / 4 ; 139 / 10$ & Waste & $9 / 11$ \\
\hline Pride & Frequent & \multirow{3}{*}{ Will } & \multirow{3}{*}{$\begin{array}{l}\text { 134/2; } \\
\text { 135/1/2/4/5/6/7/8/11/12/14; } \\
\text { 136/2/3/5/6/14; 143/13 }\end{array}$} \\
\hline Proud & Frequent & & \\
\hline Rare & 21/7; 52/5; 56/14;130/13 & & \\
\hline Right & $17 / 11$ & & \\
\hline
\end{tabular}

Notes. " "art” appears 52 times in the Sonnets; fair, 57 times; “lovely”, 8 times; “pride”, 11 times; “proud”, 14 times; “sad”, 7 times; "true”, 38 times; and "truth”, 24 times.

Shakespeare's Sonnets is rich in wordplay, which makes its translation extremely challenging. It is not easy to tell exactly how many pun words Shakespeare used in his sonnets, or how many times Shakespeare punned in the sonnets, because "every reading (and even more every performance) is a recreation, a fresh 
attempt to interpret Shakespeare's intention” (Mahood, 1968, p. 164). According to the authors' most preservative count based on the table (frequent is counted three times only), Shakespeare's Sonnets have at least 45 pun words, and he punned on them for at least 90 times. If we put those frequently appeared pun words into consideration, the number would be over 300. Sonnet 29 is a sonnet of state, since it played on "state" three times; sonnet 43 is a poem of shadow, because it played on "shadow" three times. Sonnet 132 is a sonnet of "mourning", since it punned on "morn or mourning" three times. Sonnet 151 is a sonnet of "conscience", since it punned on "conscience" three times. Needless to mention the famous Sonnets 135 and 136, sonnets of "will”, which punned on "will” 13 times and seven times respectively. Sonnet 33 punned three times on three pun words, namely "base, son-sun, steal”. Shakespeare was indeed a great punster. Ignoring the puns, the translation of Shakespeare's Sonnets would be impossible.

\section{Puns' Functions in the Sonnets}

Puns are a frequently used rhetoric device in the sonnets. "Shakespeare... use puns extensively, for serious and comic purposes" (Bonn, 2010, p. 3). Besides comic effects, they have some other important functions. In some sonnets, puns are so significant that they are the essence of the poetry, while sometimes they cluster different images, and enrich the imagery of the poem, or they may reveal the real intention of the poet.

Puns are the poetry itself. Shakespeare was a great punster. He likes to use puns to create excellence, because "his imagination as a poet works through puns" (Mahood, 1968, p. 20). Sonnet 135 is a good example.

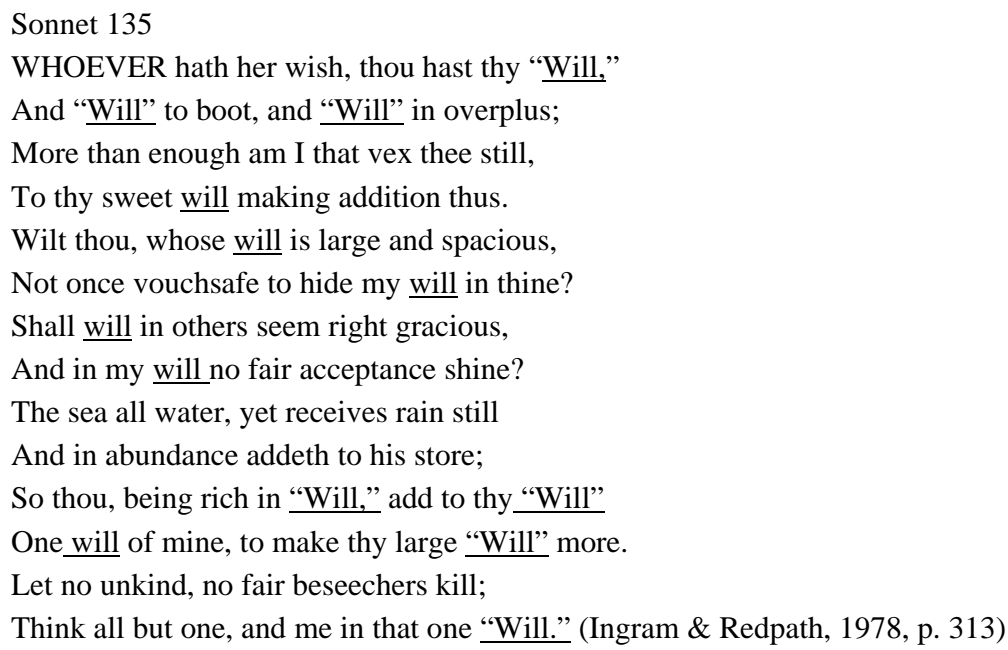

Vendler (1997, p. 32) thought this poem "perplexing, even maddening”. Virtually, it is "perplexing”, because it puns on "will" 13 times; and it is "maddening", because it puns on "will" 13 times. Sonnet 135 demonstrates the poet's talent of creating puns. It is "festivals of verbal ingenuity in which much of the fun derives from the grotesque length the speaker goes to for a maximum number and concentration of puns on will" (Booth, 1977, p. 33). In the short sonnet of 14 lines, the poet made puns on "will” thirteen times, making a pun in almost every line. The pun word, will, has at least seven meanings: (1) one's will, what one wishes to have or to do; (2) the auxiliary verb; (3) sexual lust; (4) the male sex organ; (5) the female sex organ; and (6) William. Undoubtedly, "will" is the key to the theme of the sonnet. In addition to this, the first and third quatrain used the same rhyme, i.e., "will, still" and "still, will”, while the couplet rhymed with "kill, will”. The rhyming "will" not only offers a clue for understanding the sonnet, but also contributes for the music of the 
poem. Without "will”, the "will” sonnet will lose all its poetry and pleasure, become tasteless, thus any translation which neglects "will” will fail.

Puns cluster together certain images which is made more compact through wordplay. "A double meaning acts as the quickly turned surfaces of an oarblade to move the poet's mind along the current of his thought from one image to another” (Mahood, 1968, p. 22).

\title{
Sonnet 2
}

WHEN forty winters shall beseige thy brow, And dig deep trenches in thy beauty's field,

Thy youth's proud livery, so gazed on now,

Will be a tatter'd weed, of small worth held: (Ingram \& Redpath, 1978, p. 9)

The pun word "field" has three senses: (1) a battle field, which is related with the image of "besiege" in line one, trenches in line 2; (2) an agricultural field, which corresponds with the image of "weed" in line 4; and (3) the physical beauty, which links the image of "thy brow" in the first line and "thy youth" in the third line. Through the pun word "field", the different images of "beauty's field", battle field, and agricultural field is clustered together, and the image was moved and transferred quickly among the battle field, agricultural field to the beauty's field, and fell upon the sense of "beauty's field". The word "field" enriches the imagery of the sonnet. Translators cannot thus not possibly well translate the sonnet while neglecting the pun.

Puns, or double entendre, have more than one meaning, thus they are a perfect device to reveal the writer's real intention and mind.

\author{
Sonnet 138 \\ WHEN my love swears that she is made of truth \\ I do believe her, though I know she lies, \\ That she might think me some untutor'd youth, \\ Unlearned in the world's false subtleties. \\ Thus vainly thinking that she thinks me young, \\ Although she knows my days are past the best, \\ Simply I credit her false speaking tongue: \\ On both sides thus is simple truth suppress'd. \\ But wherefore says she not she is unjust? \\ And wherefore say not I that I am old? \\ $\mathrm{O}$, love's best habit is in seeming trust, \\ And age in love loves not to have years told: \\ Therefore I lie with her and she with me, \\ And in our faults by lies we flatter’d be. (Ingram \& Redpath, 1978, p. 319)
}

Here, the word "lie" has double meanings: (1) to tell a lie; and (2) to lie with some man. It is not easy to tell which meaning is primary, which is secondary, or which is intended, and which is unintended. However, Shakespeare must intend one of the two, or both. Thus, the pun reveals the real intent of the poet. And the pun did not cause the awkwardness that a direct expression would cause. It is very difficult, in many instances, which is the intended meaning. Thus, one cannot neglect the puns in translating the sonnets. By neglecting the puns, or translating only one of the pun's multiple meanings, one is in fact risking sacrificing the intended meaning, while preserving a superficial one. One may miss the chance to translate the true Shakespeare, thus, miss the opportunity to approach the inner side of Shakespeare. To preserve the puns in translation is to 
preserve for the target readers the right of understanding the original and appreciating the original as the original readers.

\section{Puns Were not Given Enough Attention in Chinese Translation}

Shakespeare's Sonnets was first introduced into China in 1928 by a young poet ZHU Xiang. The first complete Chinese version appeared in 1950, when TU An published his translation of Shakespeare's Sonnets. Within a few years, YU Er-chang and LIANG Shi-qiu each published their own full translation in Taiwan. Up to now, there have emerged nine complete translations, as is shown in Table 2.

Table 2

Nine Chinese Versions of Shakespeare's Sonnets (ZHANG, 2007)

\begin{tabular}{|l|l|c|}
\hline \multicolumn{1}{|c|}{ Translator } & \multicolumn{1}{|c|}{ Publishing house } & Year \\
\hline TU An & Shanghai Translation Publishing House (Shanghai) & 1950 \\
\hline YU Er-chang & World Book Publishing House (Taibei) & 1961 \\
\hline LIANG Shi-qiu & The Far East Book Company (Taibei) & 1968 \\
\hline YANG Xi-ling & Inner Mongolia People’s Publishing House (Hohhot) & 1980 \\
\hline LIANG Zong-dai & Sichuan People's Publishing House (Chengdu) & 1983 \\
\hline CAO Ming-lun & Lijiang Publishing House (Guilin) & 1995 \\
\hline GU Zheng-kun & Peking University Press (Beijing) & 1998 \\
\hline RUAN Shen & Hubei Education Press (Wuhan) & 2001 \\
\hline JIN Fa-shen & Guangxi Normal University Press (Guilin) & 2004 \\
\hline
\end{tabular}

The nine versions are thus the research data of the researcher. Among them, five versions paid special attention to the rhythm translation. The translators made great efforts to reproduce the rhythm of the original. TU An used the method of "Replacing Foot With Dun" to preserve the original pentameter and accomplished the first complete version of Shakespeare's Sonnets. This method was later adopted by RUAN Shen and JIN Fa-shen in each of their translations. This method aims to preserve the original foot, the basic unit of rhythm in the sonnets, by making use of Dun (顿), a concept in classical Chinese poetry, meaning pause. The translators made great efforts to use five Duns to render the original five feet in each line, while the puns were not given enough attention. LIANG Zong-dai used a different method to reproduce the original rhythm. In his version, he used 10 Chinese Characters each line, representing the 10 syllables each line of the original, thus the time of reading the lines are mostly of the same length. But the puns' translation was not given enough attention.

Shakespeare used more than 300 puns in the 154 sonnets. And puns were extremely difficult to translate. Inevitably, the translators must face the puns, and solve the difficulties posed by them in the translation process, which shall be reflected in the preface, introduction, or the notes, if the translator did make some efforts in rendering the puns. TU An's version explained the themes and his translation method in the postscript. YU Er-chang explained the publication and themes of the sonnets. LIANG Shi-qiu reviewed the publication of the sonnets, and introduced the identities of Mr. W. H., the Dark Lady, the date, sequence, and tradition of the sonnets in his preface. YANG Xi-ling, CAO Ming-lun, and JIN fa-shen introduced the themes of the sonnets in the preface respectively. LIANG Zongdai's version has no preface at all. GU Zheng-kun, in his preface, first introduced the themes, and then discussed the rhyming patterns of the sonnet translation. None of the above translators mentioned the puns' translation, one of the most difficult parts in the sonnet translation. One 
exception is RUAN Shen's version. In his seven-page preface, he spent more than six pages in discussing the date, sequence, characters, and themes of the sonnets. In the remaining one page, he saved only one paragraph to introduce his translation method "Replacing foot with Dun" and the pun's translation, in which he mentioned two puns in the sonnets and his incompetence in translating them. In the preface, introduction or postscript of the nine versions, only one mentioned the puns.

The translation notes is also a good sign to find whether the translator is aware of the puns or not. Table 3 illustrates the number of notes and pun notes appeared in the nine versions.

Table 3

Notes and Pun Notes in the Nine Versions

\begin{tabular}{|c|c|c|c|c|}
\hline Version & Notes & Pun notes & Pun word & Sonnet \\
\hline TU An (1950) & 154 & 2 & Will & 135,136 \\
\hline YU Er-chang (1961) & 154 & 2 & Will & 135,136 \\
\hline \multirow{4}{*}{ LIANG Shi-qiu (1968) } & \multirow{4}{*}{126} & \multirow{4}{*}{5} & Approve & 42 \\
\hline & & & Shadow & 43 \\
\hline & & & Will & 135,136 \\
\hline & & & Conscience & 151 \\
\hline YANG Xi-ling (1980) & 69 & 0 & --- & $\begin{array}{c}--- \\
\end{array}$ \\
\hline LIANG Zong-dai (1983) & 7 & 2 & Will & 135,136 \\
\hline \multirow{3}{*}{ CAO Ming-lun (1995) } & \multirow{3}{*}{98} & \multirow{3}{*}{4} & Engraft & 15 \\
\hline & & & Will & 135,136 \\
\hline & & & Conscience & 151 \\
\hline \multirow{2}{*}{ GU Zheng-kun (1998) } & \multirow{2}{*}{19} & \multirow{2}{*}{4} & Will & $133,135,136$ \\
\hline & & & Conscience & 151 \\
\hline RUAN Shen (2001) & 0 & 0 & ---- & $\begin{array}{ll}--- \\
\end{array}$ \\
\hline JIN Fa-shen (2004) & 18 & 2 & Will & 135,136 \\
\hline
\end{tabular}

LIANG Shi-qiu made five pun notes, which is the most among the nine versions. Compared with the total number of puns in the sonnets, it is quite marginal. YANG Xi-ling and RUAN Shen made not a single pun note in their versions. Except them, the other seven versions all made notes on "will" in Sonnets 135 and 136. And three versions made a note on "conscience" in Sonnet 151. Altogether, only five pun words, namely, will, approve, shadow, conscience, and engraft, were noted in the nine versions, while the total number of pun words in the sonnets is 45 . In other word, less than $9 \%$ of the total number of puns was noted by the nine translators. It is not risky to conclude that the puns are mostly ignored by the translators.

\section{Conclusions}

Pun is widely-used, and thus an important stylistic feature in the sonnets. The puns have various functions in the sonnets. However, in its Chinese translation, puns are not given enough attention. Puns are so important for Shakespeare's Sonnets. And it is fairly significant to give them special attention in translation. All translators of the Sonnets shall try their best to preserve, and have no right to discard them. It is the translator's responsibility to preserve the stylistic features of the original. As Tytler (2007) pointed out "that the style and manner of writing should be of the same character with that of the original” (p. 9). Any translation which fails to preserve the puns is unfaithful to the original. 


\section{References}

Bonn, J. D. (Ed.). (2010). A comprehensive dictionary of literature. Chandigarh: Abhishek Publications.

Booth, S. (1977). Shakespeare's sonnets. New Haven: Yale University Press.

Drabble, M. (Ed.). (2000). The Oxford companion to English literature (6th ed.). Oxford: Oxford University Press. Ingram, W. G., \& Redpath, T. (Eds.). (1978). Shakespeare's sonnets. London: Hodder And Stoughton. LI, X. H. (Ed.). (2000). English rhetorics. Shanghai: Shanghai Foreign Languages Teaching and Research Press. Mahood, M. M. (1968). Shakespeare's wordplay. London: Methuen \& Co. LTD..

Ridden, G. M. (1982). York notes on Shakespeare’s sonnets. Harlow: York Press.

Tytler, A. F. (2007). Essay on the principles of translation. Beijing: Foreign Language Teaching And Research Press. Vendler, H. (1997). The art of Shakespeare's sonnets. Cambridge: Harvard University Press.

ZHANG, C. Z. (2007). A study on replacing foot with dun-From the perspective of Shakespeare sonnets' Chinese translation (Hebei University, Baoding). 